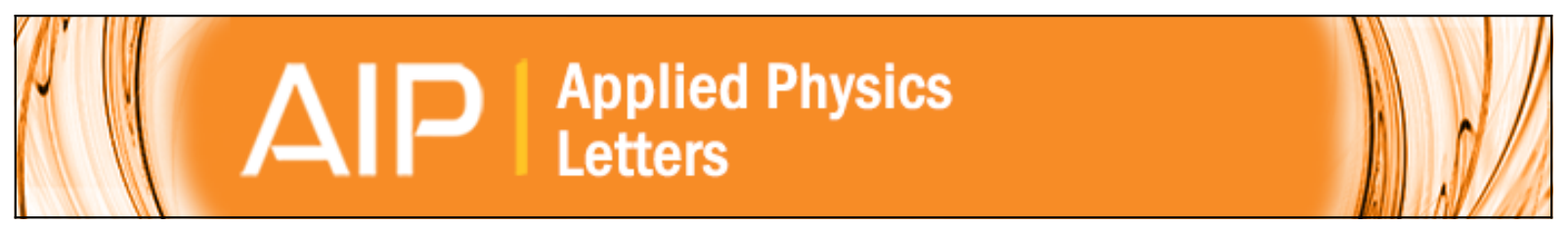

\title{
Suppression of ion-implantation induced porosity in germanium by a silicon dioxide capping layer
}

Tuan T. Tran, Huda S. Alkhaldi, Hemi H. Gandhi, David Pastor, Larissa Q. Huston, Jennifer Wong-Leung,

Michael J. Aziz, and J. S. Williams

Citation: Applied Physics Letters 109, 082106 (2016); doi: 10.1063/1.4961620

View online: http://dx.doi.org/10.1063/1.4961620

View Table of Contents: http://scitation.aip.org/content/aip/journal/apl/109/8?ver=pdfcov

Published by the AIP Publishing

\section{Articles you may be interested in}

Porosity as a function of stoichiometry and implantation temperature in $\mathrm{Ge} / \mathrm{Si} 1-\mathrm{xGex}$ alloys

J. Appl. Phys. 119, 094303 (2016); 10.1063/1.4942995

On the limits to Ti incorporation into Si using pulsed laser melting

Appl. Phys. Lett. 104, 112102 (2014); 10.1063/1.4868724

Fabrication and subband gap optical properties of silicon supersaturated with chalcogens by ion implantation and pulsed laser melting

J. Appl. Phys. 107, 123506 (2010); 10.1063/1.3415544

Nanostructuring in Ge by self-ion implantation

J. Appl. Phys. 107, 084314 (2010); 10.1063/1.3372757

High-energy ion-implantation-induced gettering of copper in silicon beyond the projected ion range: The transprojected-range effect

J. Appl. Phys. 88, 5645 (2000); 10.1063/1.1316054

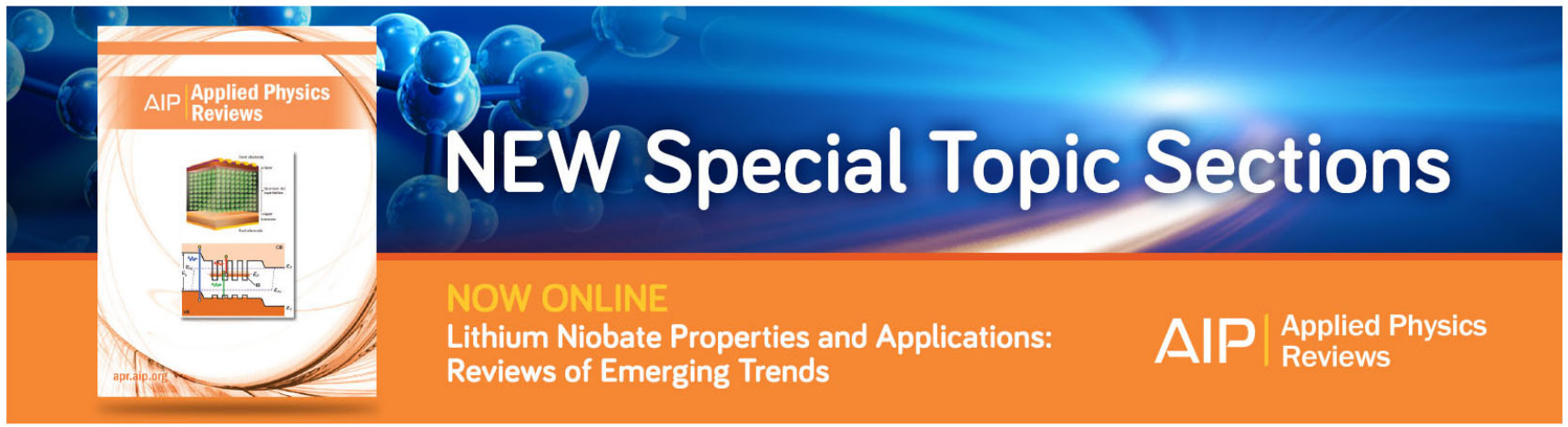




\title{
Suppression of ion-implantation induced porosity in germanium by a silicon dioxide capping layer
}

\author{
Tuan T. Tran, ${ }^{1, a)}$ Huda S. Alkhaldi, ${ }^{1}$ Hemi H. Gandhi, ${ }^{2}$ David Pastor, ${ }^{2}$ Larissa Q. Huston, ${ }^{1}$ \\ Jennifer Wong-Leung, ${ }^{1}$ Michael J. Aziz, ${ }^{2}$ and J. S. Williams ${ }^{1}$ \\ ${ }^{1}$ Department of Electronic Materials Engineering, Research School of Physics and Engineering, \\ Australian National University, Canberra, Australian Capital Territory 0200, Australia \\ ${ }^{2}$ Harvard John A. Paulson School of Engineering and Applied Sciences, Cambridge, \\ Massachusetts 02138, USA
}

(Received 15 July 2016; accepted 10 August 2016; published online 24 August 2016)

\begin{abstract}
Ion implantation with high ion fluences is indispensable for successful use of germanium (Ge) in the next generation of electronic and photonic devices. However, Ge readily becomes porous after a

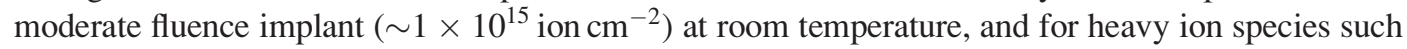
as tin $(\mathrm{Sn})$, holding the target at liquid nitrogen $\left(\mathrm{LN}_{2}\right)$ temperature suppresses porosity formation only up to a fluence of $2 \times 10^{16}$ ion $\mathrm{cm}^{-2}$. We show, using stylus profilometry and electron microscopy, that a nanometer scale capping layer of silicon dioxide significantly suppresses the development of the porous structure in Ge during a $\mathrm{Sn}^{-}$implant at a fluence of $4.5 \times 10^{16}$ ion cm $^{-2}$ at $\mathrm{LN}_{2}$ temperature. The significant loss of the implanted species through sputtering is also suppressed. The effectiveness of the capping layer in preventing porosity, as well as suppressing sputter removal of Ge, permits the attainment of an implanted Sn concentration in Ge of $\sim 15$ at.\%, which is about 2.5 times the maximum value previously attained. The crystallinity of the Ge-Sn layer following pulsedlaser-melting induced solidification is also greatly improved compared with that of uncapped material, thus opening up potential applications of the Ge-Sn alloy as a direct bandgap material fabricated by an ion beam synthesis technique. Published by AIP Publishing.
\end{abstract}

[http://dx.doi.org/10.1063/1.4961620]

As the semiconductor community moves beyond silicon (Si) technology, germanium $(\mathrm{Ge})$ is becoming an excellent material for future generations of both electronic and photonic devices. To realise broad applications of Ge, there has been wide demand for very high fluence ion implantation in the material. For example, highly conductive ultra-shallow junctions are required for the realisation of Ge metal-oxidesemiconductor field-effect transistors (MOSFETs) in the sub$22 \mathrm{~nm}$ technology node. ${ }^{1}$ Whereas the implantation doping process for a reliable $\mathrm{p}^{+}$Ge channel has been achieved, ${ }^{2,3}$ the $\mathrm{n}^{+}$doping procedure is severely compromised at high implant fluences of heavy elements, particularly antimony (Sb), in terms of the crystal quality of the near-surface region. Room temperature (RT) implantation of $\mathrm{Sb}$, even at moderate

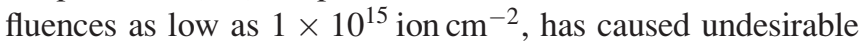
microstructural features such as surface craters or roughness. ${ }^{4,5}$ These morphological features that develop under heavy ion bombardment relate to the development of porosity in implanted Ge and are irreversible. They cannot be removed by conventional solid phase epitaxy regrowth techniques. ${ }^{4,6}$

Ge structures also have great potential as a gain medium for Si CMOS compatible laser devices. ${ }^{7,8}$ These devices can be used in optical interconnection for next generation computing. In spite of the indirect bandgap of Ge, the energy difference between the $L$ valley (indirect) and the $\Gamma$ valley (direct) is relatively small $(0.14 \mathrm{eV})$. A direct bandgap material can be obtained by either applying a sufficient biaxial tensile strain on the (100) planes of the Ge substrate ${ }^{9-11}$ or

\footnotetext{
${ }^{\text {a) }}$ Author to whom correspondence should be addressed. Electronic mail: tuan.tran@anu.edu.au
}

alloying Ge with tin (Sn) at a Sn content of $>6.5$ at.\%. ${ }^{12}$ For the latter concept, an optically pumped laser device fabricated from a Ge-Sn alloy with a Sn content of 12.6 at.\% has been demonstrated. ${ }^{13}$ To induce such a Ge-Sn direct band gap transition, non-equilibrium fabrication techniques must be employed as the required $\mathrm{Sn}$ content is much greater than the equilibrium $\mathrm{Sn}$ solubility limit in $\mathrm{Ge}$ of 0.5 at.\%. Most commonly, Ge-Sn alloys are grown by a non-equilibrium epitaxy technique such as molecular beam epitaxy ${ }^{14}$ or chemical vapour deposition, ${ }^{13,15}$ which usually involves somewhat sophisticated growth processes and often exotic chemicals. Recently, there have been several efforts to fabricate the material with a more robust, industrially relevant method using ion implantation in combination with nanosecond pulsed laser melting (PLM). ${ }^{16-18}$ For example, a good quality Ge-Sn alloy with a $\mathrm{Sn}$ concentration greater than 6 at. $\%$ has been recently obtained using PLM, ${ }^{18}$ demonstrating the potential of this approach. It was shown, however, that achieving Sn concentrations in Ge higher than about 6 at.\% through ion implantation is severely hindered by a high sputtering effect in Ge and the onset of ionimplantation induced porosity once the $\mathrm{Ge}$ is rendered amorphous (a-Ge). ${ }^{18}$

It has previously been found that irradiation-induced porosity is favoured in the range of implant temperatures between $\sim-80^{\circ} \mathrm{C}$ and $\sim 200{ }^{\circ} \mathrm{C} .{ }^{19-21}$ The onset of porosity can be suppressed by undertaking implants outside of this unfavourable temperature window. At elevated temperatures above $200{ }^{\circ} \mathrm{C}$, the $\mathrm{Ge}$ substrate remains crystalline due to the recombination of mobile vacancies and interstitials. It is not rendered amorphous and hence porous. ${ }^{6,19}$ However, for 
implant elements with high diffusivity and/or limited solubility in $\mathrm{Ge}$, notably $\mathrm{Sb}$ and $\mathrm{Sn}$, high temperature implantation makes it difficult to control the impurity profiles as a result of enhanced diffusion. Furthermore, preserving a nonequilibrium process for Ge-Sn synthesis is impractical at elevated temperature. At implant temperatures lower than $-80^{\circ} \mathrm{C}$, porosity can be suppressed or pushed to a higher fluence offset due to inefficient migration and clustering of vacancies in a-Ge. ${ }^{6,19,20}$ In the case of liquid nitrogen $\left(\mathrm{LN}_{2}\right)$ temperature implantation of $\mathrm{Ge}$ in $\mathrm{Ge}$, for example, porosity does not occur up to fluences exceeding $1.0 \times 10^{17} \mathrm{ion} \mathrm{cm}^{-2}$. However, for $\mathrm{LN}_{2}$ implantation of heavier elements such as $\mathrm{Sb}$ or $\mathrm{Sn}$, porosity occurs above about $7 \times 10^{15}$ ion $\mathrm{cm}^{-2}$ and $2.0 \times 10^{16}$ ion $\mathrm{cm}^{-2}$, respectively, thus limiting obtainable impurity concentrations in Ge. ${ }^{18,22}$

In this letter, we illustrate the limit that porosity imposes on the retained implant concentration and demonstrate a simple and yet effective solution to drastically suppress the formation of porosity during $\mathrm{Sn}$ implantation at $\mathrm{LN}_{2}$ temperature. Before implantation, selected $\mathrm{Ge}$ substrates were deposited with $\sim 40 \mathrm{~nm}$ of silicon dioxide $\left(\mathrm{SiO}_{2}\right)$ by plasma enhanced chemical vapour deposition. The encapsulation layer thickness was chosen to be thick enough to survive its gradual erosion by the ion beam at high fluence. To ensure that pristine and capped Ge substrates were implanted under the exact same conditions, both samples were placed adjacent to each other on the implant sample holder. The implantation of Sn was conducted with a low energy implanter at energies of $100-120 \mathrm{keV}$ at $\mathrm{LN}_{2}$

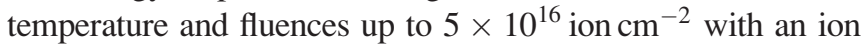
flux of $1.4 \times 10^{13}$ ion $\mathrm{cm}^{-2} \mathrm{~s}^{-1}$. According to the Stopping and Range of Ions in Matter simulation (SRIM), the projected range of the $\mathrm{Sn}$ ions in $\mathrm{Ge}$ is $34.6 \mathrm{~nm}$ and the peak concentration of

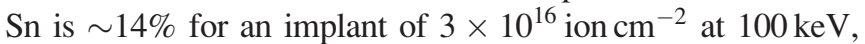
where the density of bulk Ge of $4.41 \times 10^{22}$ atom $\mathrm{cm}^{-3}$ was used to calculate the Sn concentration. Physical characterisation of the as-implanted samples was carried out using a stylus profilometer, Rutherford backscattering spectrometry (RBS), scanning electron microscopy (SEM), and transmission electron microscopy (TEM).

In Fig. 1, we illustrate the effect of the onset of porosity on the impurity concentration (as measured by RBS) for $100 \mathrm{keV} \mathrm{Sn}$ implanted $\mathrm{Ge}$ at $\mathrm{LN}_{2}$ temperature (square-green). For uncapped $\mathrm{Ge}$, beyond about $2 \times 10^{16}$ ion cm$^{-2}$, nearsurface morphological changes begin to occur with the initial formation of shallow pits that grow deeper with higher implant fluence. ${ }^{18}$ At a fluence of $3 \times 10^{16}$ ion cm $^{-2}$, a sponge-like structure (see SEM inset in Fig. 1) fully develops with a significantly increased surface area, which then further enhances the sputtering of the structure and the loss of the implanted Sn. The combination of porosity and sputtering in Ge has a pronounced impact on the achievable Sn concentration and the subsequent crystal quality following PLM-induced resolidification. As shown in Ref. 18, porosity in Ge is irreversible: it is not possible to fully recover the lattice structure by either solid phase ${ }^{4,6}$ or liquid phase epitaxial regrowth. ${ }^{18}$ As a result of these complications, studies on suppression of porosity in Ge in the high fluence regime are of utmost importance for the potential use of the material in advanced applications. Nevertheless, Ge porosity studies so far have focused on the physical mechanism or the implant conditions under which

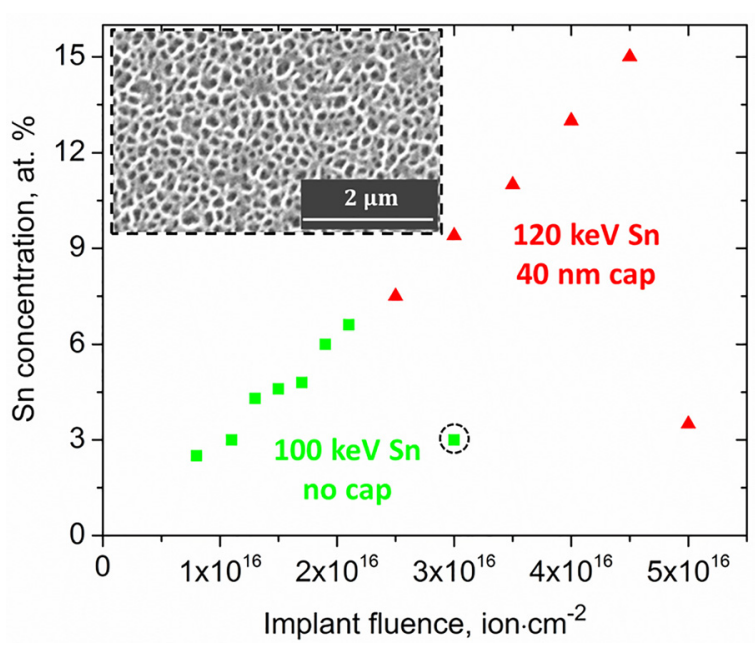

FIG. 1. A plot showing the variation of peak Sn concentration as a function of implant fluence at the implant energy of $100 \mathrm{keV}$ without a cap (squaregreen) and at $120 \mathrm{keV}$ with a cap (triangle-red). Inset figure is a SEM micrograph of the $3 \times 10^{16}$ ion $\mathrm{cm}^{-2}$ sample without a cap, showing a totally porous surface structure.

porosity occurs..$^{20,21}$ Little is known about possible ways to prevent or delay the onset of porosity, which is the main focus of the current study.

Fig. 1 also shows the increasing Sn concentration that is measured for the case of a cap, where there is no observed porosity or swelling as illustrated later. In this case, the distribution and concentration of $\mathrm{Sn}$ in Ge after implantation has been characterised by the RBS/channelling technique, in which a $2 \mathrm{MeV}^{4} \mathrm{He}^{+}$beam was used for this purpose. In

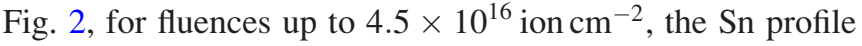
as measured by RBS is Gaussian-like and the Sn concentration increases with increasing fluence as expected for a nonporous layer in which sputter erosion is small. The peak Sn concentration in the $4.5 \times 10^{16} \mathrm{ion} \mathrm{cm}^{-2}$ sample, as fit to the RBS spectrum by the RUMP simulation program, is $\sim 15$ at. \% which is close to 2.5 times higher than previously achieved. ${ }^{18}$ However, for the highest fluence sample

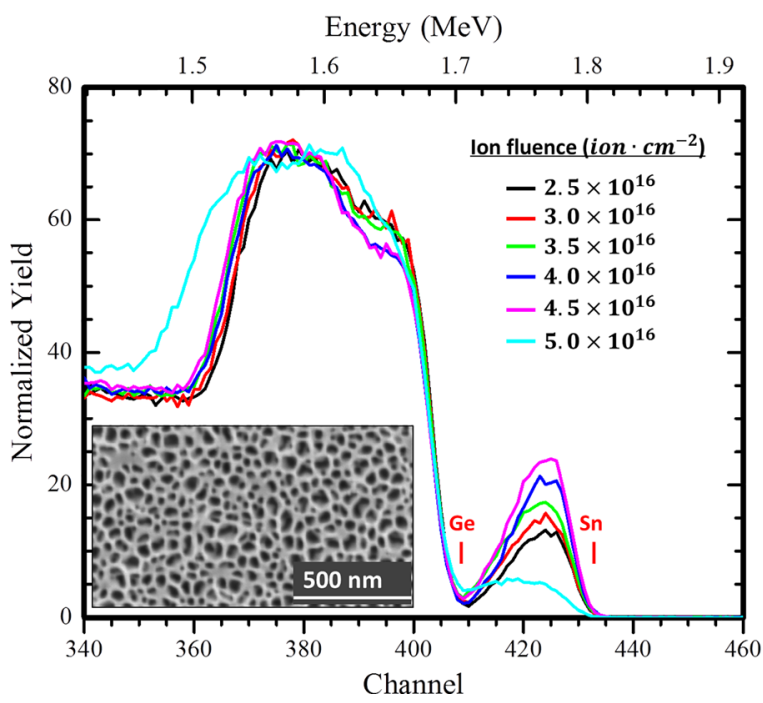

FIG. 2. RBS/channelling spectra of the Ge samples with capping layers,

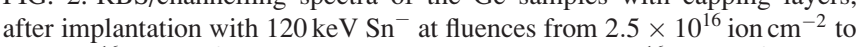

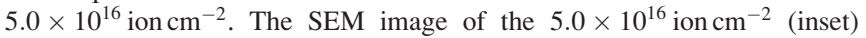
shows a porous surface if the capping layer has been sputtered away. 


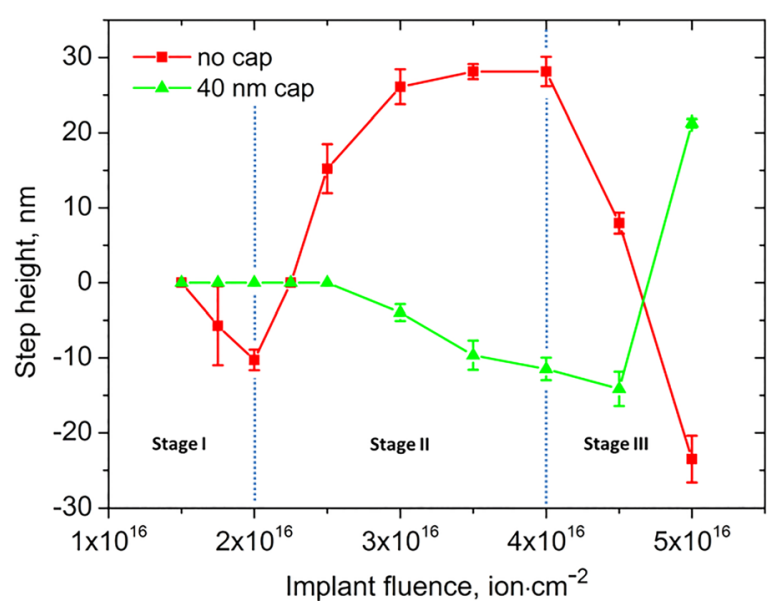

FIG. 3. Height differences between the un-implanted and implanted regions as a function of implant fluence for the samples without a capping layer (square-red) and samples with a capping layer (triangle-green). The stylus was scanned from the unimplanted area to the implanted area.

$\left(5.0 \times 10^{16}\right.$ ion $\left.\mathrm{cm}^{-2}\right)$, the surface is decidedly porous, as shown by the SEM image in the inset of Fig. 2, most likely due to the sputter removal of the $\mathrm{SiO}_{2}$ capping layer during the final stages of the implant. The RBS/channelling spectrum of this sample is distorted and the Sn content sharply drops off to less than 4 at. \% because of porosity-enhanced sputtering effects and hence excessive Sn loss.

As a result of ion-induced porosity, there can be a significant volume expansion of the a-Ge layer following high fluence implantation. Therefore, measuring the height difference between the un-implanted and the implanted regions by a stylus profilometer is a straightforward way to investigate porosity and its onset with fluence. In Fig. 3, we show the step height as a function of $120 \mathrm{keV} \mathrm{Sn}^{-}$ion fluence for samples without a $\mathrm{SiO}_{2}$ capping layer (squarered) and samples with such a layer (triangle-green). A thick silicon mask was placed partly over the samples during implantation to give a sharp transition between the two areas. The data in Fig. 3 were acquired by scanning the stylus from the un-implanted to the implanted regions. For the lowest range of the implant fluences in Fig. 3 (stage I: fluence $\leq 2 \times 10^{16}$ ion $^{-2}$ ), the step height of the implanted capped samples is largely unchanged since there is no sputtering of the underlying Ge when a cap is used effectively. The step height of the uncapped samples, however, monotonically decreases with increasing implant fluence at a rate of about $5.13 \mathrm{~nm} / 1 \times 10^{16}$ ion $\mathrm{cm}^{-2}$. Sputtering is the only effect involved in this fluence range since there is no evidence of porosity at such fluences as shown in Ref. 18. In stage II, the samples without the capping layer exhibit a significant surface expansion as indicated by a large increase in the step height. In spite of sputtering and surface erosion, the porosity dominates in this stage, giving rise to a step height that reaches $28 \mathrm{~nm}$, at which point it appears to saturate $\left(3-4 \times 10^{16}\right.$ ion $\left.\mathrm{cm}^{-2}\right)$. Beyond a fluence of about $4 \times 10^{16}$ ion $\mathrm{cm}^{-2}$ (stage III), where porosity saturates, sputter erosion begins to dominate and increases with fluence. Indeed, the measured step height is reduced to $\sim-24 \mathrm{~nm}$ below the original Ge surface. On the other hand, on the samples with the capping layer, no volumetric expansion can be detected: the step height shows an almost linear reduction with fluence of $\sim 3.1 \mathrm{~nm} / 1$ $\times 10^{16}$ ion $\mathrm{cm}^{-2}$, consistent with sputter erosion of the cap. Essentially, the thin capping layer appears to be very effective at suppressing $\mathrm{Ge}$ pore formation. For the

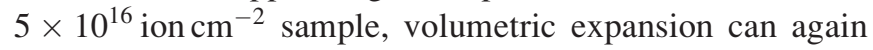
be detected since the cap has been sputtered off and Ge is rendered porous. It is noteworthy that the use of a $\mathrm{SiO}_{2}$ cap in Ge implantation study has been previously reported. ${ }^{4}$ However, the effect of the cap in suppressing porosity was unclear from this study as the data showed almost no morphological differences between samples with the cap and samples without the cap, presumably because the implantation in that experiment was done at RT. In fact, our data indicate that the cap is not as effective as the implant temperature increases. Above $-50{ }^{\circ} \mathrm{C}$, the effectiveness of the cap completely diminishes, particularly for heavy implant species such as $\mathrm{Sn}$ or $\mathrm{Sb}^{23}$

Further investigation of the samples was conducted by using electron microscopy analysis (SEM and TEM) on selected samples of interest. In Fig. 4, electron micrographs of the $3.0 \times 10^{16}$ ion $\mathrm{cm}^{-2}$ samples without $\mathrm{a} \mathrm{SiO}_{2}$ capping layer (Figs. 4(a) and 4(d)) and with a capping layer (Figs. 4(b) and 4(e)) are presented for comparison. The samples without the cap clearly formed a sponge-like structure on the surface (Fig. 4(a)), indicating extensive porosity at this fluence. The cross-sectional TEM (XTEM) image of the same sample (Fig. 4(d)) shows that the porous region extends from the surface to a depth of more than $130 \mathrm{~nm}$, along with an underlying

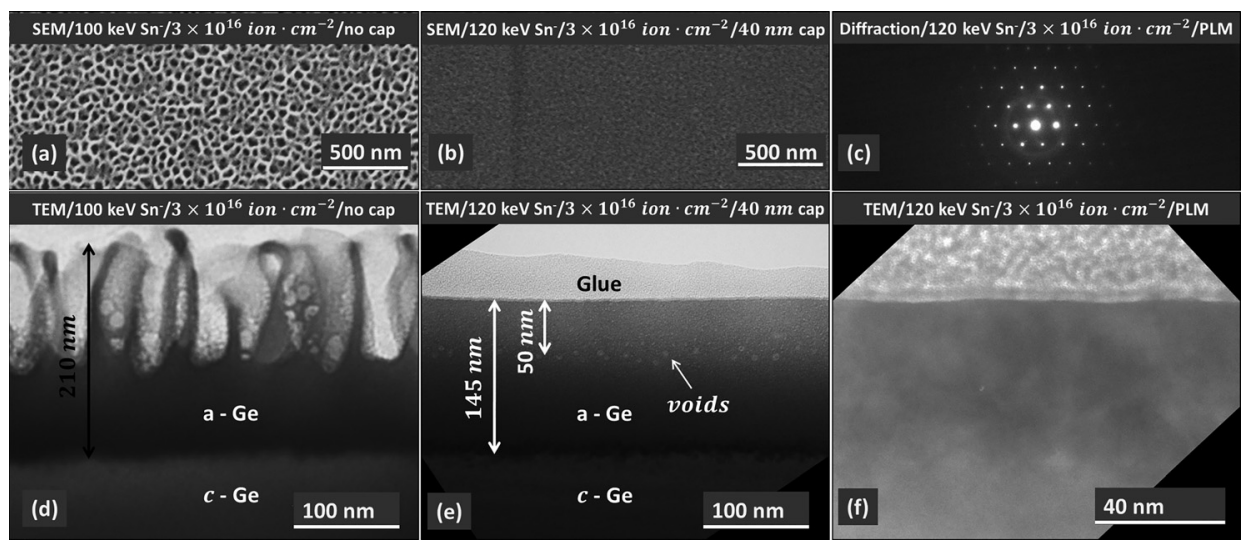

FIG. 4. Plan-view SEM micrographs and cross-section TEM (XTEM) micrographs of the $3.0 \times 10^{16}$ ion $\mathrm{cm}^{-2}$ samples as-implanted without capping layer (a), (d) and with a $40 \mathrm{~nm}$ capping layer (b), (e). (c) The diffraction pattern of the same capped sample following PLM and (f) is a higher magnification XTEM of this sample. The capping layer has been removed on all samples before imaging. 
layer of a-Ge $(\sim 80 \mathrm{~nm})$. The transition from a-Ge to nearsurface porosity leads to several orders of magnitude increase in the surface area which subsequently enhances the sputtering effect and reduces the retained Sn concentration to a few at. \% (Fig. 1). In terms of applications in planar electronic devices, this behaviour is totally undesirable.

In contrast, the introduction of a capping layer on the $\mathrm{Ge}$ substrates has completely suppressed porosity at a Sn fluence of $3.0 \times 10^{16} \mathrm{ion} \mathrm{cm}^{-2}$. The samples showed a perfectly smooth surface (after removal of any residual $\mathrm{SiO}_{2}$ capping layer by dipping the samples into hydrofluoric acid for $20 \mathrm{~s}$ ) with no sign of surface roughness or craters (Figs. 4(b) and 4(e)). However, Fig. 4(e) shows a band of small voids at about $50 \mathrm{~nm}$ below the surface. We suggest that these voids arise from the coalescence of vacancies produced at the depth of the maximum vacancy production in a-Ge.

For the non-porous $3.0 \times 10^{16}{\text { ion } \mathrm{cm}^{-2}}_{\text {sample, the }}$ sample was then PLMed with a single laser shot of $0.4 \mathrm{~J} \mathrm{~cm}^{-2}$ from a frequency tripled Nd:YAG laser $(355 \mathrm{~nm}$, $4 \mathrm{~ns}$ duration). The voids from $2 \mathrm{~nm}$ to $7 \mathrm{~nm}$ in diameter have been removed after PLM as shown in Fig. 4(f). The diffraction pattern (Fig. 4(c)) and the XTEM figure (Fig. 4(f)) demonstrate a monocrystalline diamond cubic Ge-Sn layer after PLM. Thus, voids formed during ion implantation do not appear to prevent the formation of good quality epitaxial crystalline material after PLM. A good quality crystallisation process such as the case in Fig. 4(f) will give the opportunity to explore a direct band gap Ge-Sn semiconductor.

Another advantage of a low mass capping layer such as $\mathrm{SiO}_{2}$ is minimization of impurity loss due to sputtering. According to SRIM, ${ }^{24}$ this can reduce the sputter yield of Sn in Ge from $0.44 \mathrm{Sn}$ atom ion ${ }^{-1}$ (for an uncapped 7 at. \% GeSn alloy) to almost zero (for an intact capping layer). A possible undesirable issue of the $\mathrm{SiO}_{2}$ capping layer is the recoil implantation of unintended species from the capping layer, $\mathrm{Si}$ and $\mathrm{O}$, into the underlying a-Ge. Nevertheless, SRIM simulation indicates that the recoiled concentration of $\mathrm{Si}$ and O drops off to $\sim 37 \%$ (penetration depth: $1 / e$ ) at the depth of $\sim 2 \mathrm{~nm}$ and to $\sim 1.8 \%\left(1 / e^{4}\right)$ at the depth of $\sim 4 \mathrm{~nm}$ below the a-Ge surface. If necessary, such a layer could be easily removed by a controlled reactive ion etching process prior to PLM without considerably reducing the Sn content.

It is worth noting that porosity has previously been shown to initiate from the surface as demonstrated in selfion irradiation of Ge in Ref. 25. Indeed, it is demonstrated ${ }^{20}$ that vacancies preferentially form clusters and voids at the a-Ge surface during ion irradiation leading to pores that intersect the surface and develop with increasing fluence into a porous structure like that in Fig. 4(d). Based on this initial development of porosity, the data in this report can be interpreted as showing that a $\mathrm{SiO}_{2}$ capping layer suppresses vacancy clustering under a cap at the a-Ge surface and hence surface-initiated development of porosity. The reason for the inhibition of vacancy clustering (void formation) under a cap as the initiator of porosity is unclear. However, it may be related to the confining effect of the cap in suppressing ion-induced vacancy migration and agglomeration at the surface. ${ }^{23}$ Further studies would be needed to resolve this issue.
In conclusion, we have shown that capping Ge with a thin $\mathrm{SiO}_{2}$ layer extends the fluence of heavy elements that can be implanted at $\mathrm{LN}_{2}$ temperature without the development of porosity from $2.5 \times 10^{16}$ ion cm $^{-2}$ to $4.5 \times 10^{16}$ ion $\mathrm{cm}^{-2}$. This method also suppresses the loss of implanted species by sputter removal. This approach has permitted us to develop implanted Sn concentrations up to 15 at. \%, which is close to 2.5 times that previously achieved without a capping layer. This finding not only aids producing high $\mathrm{Sn}$ content $\mathrm{Ge}-\mathrm{Sn}$ alloys as a group IV direct bandgap semiconductor by ion beam synthesis but also adds important insight into porous structure development in ion implanted Ge.

The authors would like to acknowledge the Australian Research Council for the funding support, the National Collaborative Research Infrastructure Strategy for the access to the Australian National Fabrication Facility and the Heavy Ion Accelerator Facility. D.P. acknowledges the support to perform part of the research described in this paper to the grant from the Programa Nacional de movilidad de recursos humanos del Plan Nacional I+D+i 2008-2011 of the MEC (Grant No. EX-2010-0662) and also to the grant from the U.S. Air Force Office of Scientific Research (Grant No. FA955014-1-0150).

${ }^{1}$ G. Thareja, J. Liang, S. Chopra, B. Adams, N. Patil, S. L. Cheng, A. Nainani, E. Tasyurek, Y. Kim, S. Moffatt, R. Brennan, J. McVittie, T. Kamins, K. Saraswat, and Y. Nishi, "High performance germanium n-MOSFET with antimony dopant activation beyond $1 \times 10^{20} \mathrm{~cm}^{-3}$," in IEEE International Electron Devices Meeting, 2010, p. 10.5.1.

${ }^{2}$ G. Impellizzeri, S. Mirabella, A. Irrera, M. G. Grimaldi, and E. Napolitani, J. Appl. Phys. 106, 013518 (2009).

${ }^{3}$ I. Giuliana, N. Enrico, B. Simona, P. Vittorio, C. Trudo, V. Wilfried, and P. Francesco, Appl. Phys. Express 5, 021301 (2012).

${ }^{4}$ T. Janssens, C. Huyghebaert, D. Vanhaeren, G. Winderickx, A. Satta, M. Meuris, and W. Vandervorst, J. Vac. Sci. Technol., B 24, 510 (2006).

${ }^{5}$ R. J. Kaiser, S. Koffel, P. Pichler, A. J. Bauer, B. Amon, A. Claverie, G. Benassayag, P. Scheiblin, L. Frey, and H. Ryssel, Thin Solid Films 518, $2323(2010)$.

${ }^{6}$ O. W. Holland, B. R. Appleton, and J. Narayan, J. Appl. Phys. 54, 2295 (1983).

${ }^{7}$ J. Liu, X. Sun, L. C. Kimerling, and J. Michel, Opt. Lett. 34, 1738 (2009).

${ }^{8}$ J. Michel, J. Liu, and L. C. Kimerling, Nat. Photonics 4, 527 (2010).

${ }^{9}$ M. J. Suess, R. Geiger, R. A. Minamisawa, G. Schiefler, J. Frigerio, D. Chrastina, G. Isella, R. Spolenak, J. Faist, and H. Sigg, Nat. Photonics 7, 466 (2013).

${ }^{10}$ J. Liu, X. Sun, D. Pan, X. Wang, L. C. Kimerling, T. L. Koch, and J. Michel, Opt. Express 15, 11272 (2007).

${ }^{11}$ J. R. Jain, A. Hryciw, T. M. Baer, D. A. B. Miller, M. L. Brongersma, and R. T. Howe, Nat. Photonics 6, 398 (2012).

${ }^{12}$ S. Gupta, B. Magyari-Köpe, Y. Nishi, and K. C. Saraswat, J. Appl. Phys. 113, 073707 (2013).

${ }^{13}$ S. Wirths, R. Geiger, N. v. d. Driesch, G. Mussler, T. Stoica, S. Mantl, Z. Ikonic, M. Luysberg, S. Chiussi, J. M. Hartmann, H. Sigg, J. Faist, D. Buca, and D. Grützmacher, Nat. Photonics 9, 88 (2015).

${ }^{14}$ G. He and H. A. Atwater, Phys. Rev. Lett. 79, 1937 (1997).

${ }^{15}$ C. L. Senaratne, J. D. Gallagher, L. Jiang, T. Aoki, D. J. Smith, J. Menéndez, and J. Kouvetakis, J. Appl. Phys. 116, 133509 (2014).

${ }^{16}$ A. Bhatia, W. M. Hlaing Oo, G. Siegel, P. R. Stone, K. M. Yu, and M. A. Scarpulla, J. Electron. Mater. 41, 837 (2012).

${ }^{17}$ K. Gao, S. Prucnal, R. Huebner, C. Baehtz, I. Skorupa, Y. Wang, W. Skorupa, M. Helm, and S. Zhou, Appl. Phys. Lett. 105, 042107 (2014).

${ }^{18}$ T. T. Tran, D. Pastor, H. H. Gandhi, L. A. Smillie, A. J. Akey, M. J. Aziz, and J. S. Williams, J. Appl. Phys. 119, 183102 (2016).

${ }^{19}$ B. Stritzker, R. G. Elliman, and J. Zou, Nucl. Instrum. Methods Phys. Res., Sect. B 175-177, 193 (2001). 
${ }^{20}$ H. S. Alkhaldi, F. Kremer, T. Bierschenk, J. L. Hansen, A. Nylandsted-Larsen, J. S. Williams, and M. C. Ridgway, J. Appl. Phys. 119, 094303 (2016).

${ }^{21}$ L. Romano, G. Impellizzeri, M. V. Tomasello, F. Giannazzo, C. Spinella, and M. G. Grimaldi, J. Appl. Phys. 107, 084314 (2010).

${ }^{22}$ E. Bruno, G. G. Scapellato, G. Bisognin, E. Carria, L. Romano, A. Carnera, and F. Priolo, J. Appl. Phys. 108, 124902 (2010).
${ }^{23}$ H. S. Alkhaldi, T. T. Tran, F. Kremer, and J. S. Williams, "The influence of capping layers on pore formation in Ge during ion implantation," J. Appl. Phys. (to be published).

${ }^{24}$ M. Mayer, AIP Conf. Proc. 475, 541 (1999).

${ }^{25}$ L. Romano, G. Impellizzeri, and M. G. Grimaldi, Mater. Lett. 96, 74 (2013). 